Artículo Original/ Original Article

\title{
Infecciones urinarias en niños con vejiga neurogénica y los patrones de resistencia a los uropatógenos más frecuentes
}

\author{
*Clotilde Molin, Elvira Del Valle, Lourdes González, Liliana Figueredo \\ ${ }^{1}$ SENADIS. Laboratorio de la Secretaria Nacional por los Derechos Humanos de las Personas con Discapacidad. \\ Fernando de la Mora. Paraguay \\ Cómo referenciar este artículo/ \\ How to reference this article: \\ Molin C, Del Valle E, González L, Figueredo L. \\ Infecciones urinarias en niños con vejiga neurogénica y \\ los patrones de resistencia a los uropatógenos más \\ frecuentes. Mem. Inst. Investig. Cienc. Salud. 2018; \\ 16(3): $44-50$
}

\section{R E S U M E N}

Las infecciones del tracto urinario (ITU) en niños con vejiga neurogénica, pueden producir alteraciones tanto morfológicas como funcionales, y desencadenan una respuesta inmune que no siempre es evidente. Las ITU son una de las principales causas de morbilidad y mortalidad. Resulta de suma importancia un correcto diagnóstico de las mismas, para un buen tratamiento y así evitar las complicaciones y secuelas que puedan ocasionar. El objeto del trabajo fue analizar la prevalencia y la etiología de las ITU en pacientes con vejiga neurogénica, y su patrón de resistencia. En un estudio descriptivo, retrospectivo se incluyeron 46 muestras de orina para cultivo de niños de 1 a 18 años, de ambos sexos, con vejiga neurogénica, que fueron procesadas en un laboratorio de microbiología. De 46 urocultivos, 19 correspondieron a varones (19/46) 41\% y 27 a niñas (27/46) 59\%, los niños tenían una edad promedio de $11 \pm 2$. De estos 21 resultaron positivos $(21 / 46) 46 \%$, aislando en mayor proporción $E$. coli. La frecuencia de ITU en niños con vejiga neurogénica fue de $21 / 46,46 \%$, siendo el porcentaje en este tipo de pacientes mucho más elevado que en niños que no presentan dicha anomalía. Los uropatógenos aislados con mayor frecuencia fueron $E$ coli y $K$ pneumoniae. El uso de sondas y pañales, así como la mala higiene predisponen a estas infecciones. En este estudio se vio buena sensibilidad a la nitrofurantoina y cefixima.

Palabras clave: infección urinaria, vejiga neurogénica, niños con discapacidad.

\section{Urinary tract infections in children with neurogenic bladder and resistance patterns of most frequent urological pathogens}

\section{A B S T R A C T}

Urinary tract infections (UTI) in children with neurogenic bladder can produce morphological and functional alterations, and trigger an immune response that is not always evident. The UTI are one of the main causes of morbidity and mortality. It is very important to diagnose them correctly for a good treatment and thus to avoid complications and consequences that they can cause. The objective of the study was to analyze the prevalence and etiology of the infections in patients with neurogenic bladder hospitalized in UTI, and the resistance pattern of the most frequent uropathogens. This was a descriptive, retrospective study that included 46 samples of urine culture of children from 1 to 18 years old, of both sexes, with a neurogenic bladder, which were processed in a microbiology laboratory. Of the 46 urine cultures, 19 corresponded to boys (19/46) $41 \%$ and 27 corresponded to girls (27/46) 59\%, with an age average of $11 \pm 2$. Of the total sample, 21 were positive (21/46) $46 \%$, isolating Escherichia coli in a greater proportion. The frequency of UTI in children with neurogenic bladder was of $21 / 46,46 \%$, being the percentage in this type of patients much higher than children who do not have this anomaly. The most frequently isolated uropathogens were $E$. coli and Klebsiella pneumoniae. The use of catheters and diapers, as well as bad hygiene, predispose to these infections. Good sensitivity to nitrofurantoin and cefixime was observed in this study.

Keywords: urinary infection, neurogenic bladder, children with disabilities.

Fecha de recepción: octubre 2018. Fecha de aceptación: noviembre 2018

*Autor correspondiente: Clotilde Molin. Laboratorio de la Secretaria Nacional por los Derechos Humanos de las Personas con Discapacidad. (SENADIS), Fernando de la Mora. Paraguay

Email: cottymolinar@hotmail.com 


\section{INTRODUCCION}

Se define como infección del tracto urinario (ITU) a la invasión y multiplicación, de microorganismos en la uretra, vejiga, uréter o riñones, por agentes patógenos, especialmente bacterias, que habitualmente provienen de la región perineal ${ }^{(1)}$. Pudiendo producir alteraciones tanto morfológicas o funcionales, las ITU desencadenan una respuesta inmune que no siempre es evidente ${ }^{(2)}$.

Las ITU en pediatría son muy frecuentes, ocurriendo en aproximadamente $5 \%$ de los escolares y en $2 \%$ de menores de 5 años en niños sin discapacidad, siendo Escherichia coli el germen aislado con mayor frecuencia, con un $65,7 \%$ y Klebsiella pneumoniae con $17,1 \%$, ambos de origen entérico, datos provenientes de un centro hospitalario de la ciudad de Asunción. Es la segunda causa más frecuente de infección bacteriana en niños ${ }^{(3,4,5)}$.

En un estudio bacteriológico en niños con discapacidad, realizado en México, se comprobó que el primer agente involucrado es Escherichia coli, en un $41,8 \%{ }^{(6)}$. Aunque la incidencia exacta de ITU en pediatría no se conoce bien, debido especialmente a problemas para definir cuando se trata de una infección ${ }^{(3,7)}$. En presencia de una vejiga neurogénica hay que diferenciar entre colonización, que es frecuente, e infección. La colonización bacteriana no requiere tratamiento en tanto la infección se confirma por la sintomatología ${ }^{(8)}$.

En la actualidad en Paraguay no se registran trabajos de ITU en niños con vejiga neurogénica. En un estudio realizado en Cuba con respecto a las malformaciones nefrourológicas se encontró que 57 (98,3\%) muestras correspondían a vejiga neurogénica ${ }^{(9)}$.

En un estudio realizado en España con una población de 106 pacientes con vejiga neurogénica que acudieron a consultas externas de urología, el $66 \%$ de los urocultivos fueron positivos, siendo el germen aislado con mayor frecuencia E.coli $49 \%{ }^{(10)}$.

Las manifestaciones típicas de las ITU sintomática suelen estar ausentes en estos pacientes, fenómeno que retrasa el diagnóstico. La sintomatología incluye, fiebre, dolor en vejiga o riñón, incontinencia urinaria, aumento de la espasticidad, hiperreflexia autonómica, orina turbia con mayor olor y malestar. Y se confirma con un sedimento urinario con leucocitos mayor a 50 por campo, y un cultivo positivo mayor o igual a $100.000 \mathrm{Ufc} / \mathrm{ml}$, cifras menores también pueden considerar un cultivo positivo en niños pequeños con micción frecuente, cuando el cuadro clínico es sugestivo de pielonefritis. Cabe destacar que la mayoría de las ITU asociadas con el empleo de sondas son asintomáticas ${ }^{(11,12)}$, la orina para este tipo de pacientes debe ser recolectada con un catéter nuevo, en un recipiente estéril y llevado inmediatamente al laboratorio ${ }^{(10,13)}$.

Las lesiones medulares, hidrocefalia y mielomeningocele son causas de vejiga neurogénica en niños, que experimentan complicaciones urológicas derivando en un mayor riesgo de ITU, y son la primera causa de morbilidad y mortalidad, debido al mal vaciamiento de la vejiga ${ }^{(14,15)}$.

El uso de pañales desechables y la disfunción neurógena de las vías urinarias pueden ocasionar alteraciones miccionales con imposibilidad de evacuar el contenido vesical espontáneamente, orina residual, reflujo vesico uretral, divertículos vesicales y dificultad para realizar una correcta higiene ${ }^{(6,16)}$ generando obstrucción del tracto urinario inferior, retención urinaria y distensión vesical de no mediar un método para el vaciado de la misma. El método de elección para ello es el uso de cateterismo intermitente limpio, sin embargo, durante su uso, bacterias periuretrales son inoculadas diariamente en la orina de niños con vejiga neurogénica, generando bacteriuria a pesar de no presentar clínica de $\operatorname{ITU}^{(17)}$.

Los factores de riesgo de las ITU están divididos en categorías relacionadas con:

a) Anomalías morfológicas y funcionales del tracto urinario: comprenden la disinergia post-miccional, el reflujo vesico uretral, uso de catéter urinario, litiasis y divertículos, que son clasificadas como ITU complicadas donde los uropatógenos pueden acceder a la vejiga urinaria, proliferar y producir una infección.

b) Características sociológicas y demográficas: Depende del mayor grado de dependencia del paciente, la imposibilidad de adaptación a la discapacidad y la higiene deficiente ${ }^{(14,18)}$.

El tratamiento empírico y profiláctico no está recomendado en estos pacientes con infecciones complicadas. Es necesario conocer el comportamiento clínico, microbiológico y epidemiológico de la infección urinaria para encarar el desafío de la aparición de resistencias de los uropatógenos y para reducir las complicaciones crónicas asociadas, tales como el 
deterioro anatómico y funcional del tracto urinario, la cistitis crónica intersticial, el cáncer de vejiga y el deterioro de la función renal ${ }^{(18)}$.

La ITU que se presenta en niños con anomalía importante de las vías urinarias, puede ocasionar daño renal permanente. Esta es la principal razón por la que es importante un diagnóstico precoz, un tratamiento eficaz y preciso, de modo que se puedan evitar las complicaciones y secuelas a largo plazo ${ }^{(19)}$.

El uso de cateterismo intermitente limpio (CIL) pueden promover la bacteriuria en ausencia de síntomas, por lo cual es fundamental la diferenciación entre colonización vs. infección, ya que la interpretación errónea de los episodios de bacteriuria asintomática como infección urinaria puede llevar a la utilización innecesaria de antibióticos y a la selección de microorganismos resistentes ${ }^{(20)}$.

Este estudio se llevó a cabo a fin de analizar la prevalencia de las infecciones urinarias en pacientes con vejiga neurogénica:

- analizar la etiología de los uropatógenos más frecuentes en una población con vejiga neurógena

- describir los factores de riesgos encontrados en pacientes con vejiga neurogéna y

- describir el patrón de sensibilidad/resistencia de las principales bacterias aisladas.

\section{MATERIALES Y METODOS}

Se realizó un estudio descriptivo de tipo retrospectivo en el que se incluyeron un total de 46 pacientes con vejiga neurogénica, a los que se les realizaron urocultivos. Para recoger la información se ingresó al sistema informático de admisión de los pacientes, ADMISION, donde se accedió a las historias clínicas de todos los pacientes y se seleccionaron a los niños con vejiga neurogénica.

Las orinas en estudio fueron cultivadas en medios de agar sangre y EMB, y a todos los urocultivos con crecimiento microbiano se les realizaron las pruebas de identificación por medio de pruebas convencionales, así también se determinó la sensibilidad a antimicrobianos a través del método de difusión en disco en Agar Müller-Hinton según lo establecido por Kirby Bauber ${ }^{(21)}$.

Se excluyeron los urocultivos de los pacientes con, mala toma de muestra, muestras obtenidas de bolsa colectora en pacientes sondados, mala identificación y aquellas contaminadas con más de tres especies microbianas diferentes.

Los resultados de urocultivos obtenidos se registraron en una base de datos Excel, donde fueron procesados para su análisis.

El análisis e interpretación de los datos se hizo con base en las guías de la CLSI- $2017^{(22)}$.

\section{ASPECTOS ETICOS}

El nombre del paciente se registró con el único fin de no volver a repetir la muestra. Se trabajó con códigos y en forma anónima para respetar la confidencialidad del paciente.

\section{RESULTADOS}

En este estudio participaron un total de 46 niños, de los cuales 19 eran varones (19/46) $41 \%$ y 27 eran niñas (27/46) $59 \%$, con una edad promedio de $11 \pm 2$.

De las 46 muestras procesadas para urocultivos, resultaron positivas (21/46) $46 \%$, de las cuales (10/21) $48 \%$ resultaron ser positivas en varones y $(11 / 21) 52 \%$ en niñas.

Los uropatógenos aislados provenientes de muestras de cultivo de orina de niños con vejiga neurogénica se pueden observan en la Figura 1. 


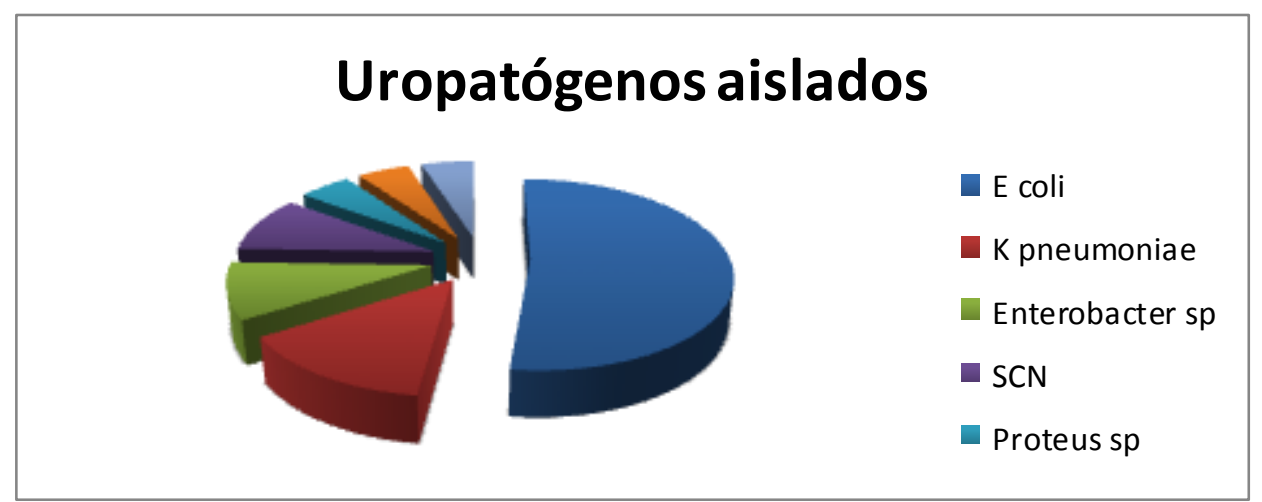

Figura 1: Uropatógenos aislados en muestras de orina cultivo provenientes de vejiga neurogénica. E.coli $(11 / 21) 52 \%, K$. pneumoniae (3/21) 14\%, Enterobacter sp (2/21) $9,5 \%$, Staphylococcus sp (coagulasa negativa) $(2 / 21) 9,5 \%$, Proteus sp $(1 / 21) 5 \%$; Serratia marcencens (1/21) 5\%, Streptococcus agalactiae (1/21) $5 \%$.

Con relación al perfil de sensibilidad de los patógenos aislados más frecuentemente se obtuvo:

a) Para Escherichia coli:

Tabla 1: Perfil de sensibilidad para E.coli, aisladas de ITU de niños con vejiga neurogénica.

\begin{tabular}{llll}
\hline Antibiótico & Resistente & Intermedio & Sensible \\
\hline Ampicilina & $(11 / 11) 100 \%$ & & \\
Cefalotina & $(6 / 11) 55 \%$ & $(2 / 11) 18 \%$ & $(3 / 11) 27 \%$ \\
Cefixima & $(1 / 11) 9 \%$ & $(1 / 11) 9 \%$ & $(9 / 11) 82 \%$ \\
Amikacina & $(1 / 11) 9 \%$ & $(2 / 11) 18 \%$ & $(8 / 11) 73 \%$ \\
Trim/sulfam & $(6 / 11) 55 \%$ & $(1 / 11) 9 \%$ & $(4 / 11) 36 \%$ \\
Nitrofurantoina & $(11 / 11) 100 \%$ & & \\
Ciprofloxacina & $(3 / 11) 27 \%$ & & $(8 / 11) 73 \%$ \\
Cefotaxima & $(1 / 11) 9 \%$ & & $(10 / 11) 91 \%$ \\
Ceftazidima & $(1 / 11) 9 \%$ & & $(10 / 11) 91 \%$ \\
\hline
\end{tabular}

b) Para Klebsiella pneumoniae

Tabla 2: Perfil de sensibilidad para Klebsiella pneumoniae, aisladas de ITU de niños con vejiga neurogénica.

\begin{tabular}{llll}
\hline Antibiótico & Resistente & Intermedio & Sensible \\
\hline Ampicilina & $(3 / 3) 100 \%$ & & \\
Cefalotina & & $(2 / 3) 67 \%$ & $(1 / 3) 33 \%$ \\
Cefixima & & $(3 / 3) 100 \%$ \\
Amikacina & & & $(3 / 3) 100 \%$ \\
Trim/sulfam & $(1 / 3) 33 \%$ & & $(2 / 3) 67 \%$ \\
Nitrofurantoina & $(1 / 3) 33 \%$ & $(1 / 3) 33 \%$ & $(1 / 3) 33 \%$ \\
Ciprofloxacina & & & $(3 / 3) 100 \%$ \\
Cefotaxima & & & $(3 / 3) 100 \%$ \\
Ceftazidima & & & $(3 / 3) 100 \%$ \\
\hline
\end{tabular}




\section{DISCUSIÓN}

Las infecciones de las vías urinarias en pacientes con vejiga neurogénica constituyen una de las causas principales de morbilidad y mortalidad. La micción incompleta, la presión intra-vesical elevada y el empleo de sondas incrementan el riesgo de ITU ${ }^{(14)}$.

De un total de 46 muestras para urocultivos provenientes de niños con vejiga neurogénica, 21 resultaron ser positivas que corresponde a una prevalencia de $46 \%$. De estas muestras $10 / 21(48 \%)$ resultaron ser positivas en los varones y $11 / 21(52 \%)$ para las niñas. Esto supone el mayor riesgo que presentan las niñas de contraer ITU, debido a la cercanía de la zona perianal con el meato urinario y la falta de higiene.

El germen aislado con mayor frecuencia fue E.coli, 11/21 (52\%), lo que se correlaciona con otros trabajos realizados por López Genaro et al, concluyendo de esta manera que la causa más común de estas infecciones en pacientes con discapacidades especiales es la contaminación fecal periuretral, el uso de pañales y la falta de una correcta higiene de los genitales, lo que los hace muy propensos a la colonización e invasión bacteriana de dicha zona ${ }^{(6)}$.

Teniendo en cuenta los factores de riesgo vistos es importante orientar y continuar avanzando en la educación del paciente y sus familiares, en cuanto a las medidas higiénicas y sanitarias, con el fin de poder minimizar las ITU por colonización de agentes bacterianos.

Con respecto a los patrones de resistencia para E.coli observamos que todas las cepas son resistentes a ampicilina $11 / 11(100 \%)$. Se puede rescatar antibióticos como nitrofurantoina donde la sensibilidad es $11 / 11(100 \%)$. La sensibilidad para cefalosporinas frente a este germen es de $91 \%$ para cefotaxima y ceftazidima, este se debe a que las enterobacterias actualmente han presentado un incremento en la resistencia a las cefalosporinas mediadas por plásmido que producen cefalosporinasas ${ }^{(21)}$, y a la presencia de enzimas del tipo beta lactamasas de espectro extendido que las hidrolizan; la sensibilidad va decayendo en el $82 \%$ para cefixima y aún más en el $27 \%$ para cefalotina.

Ante la ciprofloxacina la sensibilidad es de $73 \%$, así también como para la amikacina, aunque para este último no son recomendados debido a los efectos nefrotóxicos que presentan ${ }^{(23)}$. Siempre teniendo en cuenta el riesgo -beneficio que esto implicaría para los pacientes.

Debe destacarse siempre la importancia de efectuar un diagnóstico correcto de ITU a fin de evitar un tratamiento inadecuado, que pueda alterar o modificar la flora bacteriana por el uso de antibióticos en forma empírica ${ }^{(24)}$.

\section{CONCLUSION}

La prevalencia de ITU en pacientes con vejiga neurogénica es de $21 / 46,46 \%$, con lo que podemos determinar que el porcentaje en este tipo de pacientes es mucho más elevado que en ITU en niños que no presentan dicha anomalía, siendo de aproximadamente $5 \%$ en niños sin discapacidad.

Los uropatógenos aislados con mayor frecuencia en los niños fueron $E$ coli y $K$ pneumoniae, con $52 \%$ y $14 \%$ respectivamente, lo cual concuerda con los resultados obtenidos en España, en el cual el germen aislado con mayor frecuencia fue E.coli en un $49 \%$, lo que indica que la mayoría de las infecciones provienen de la colonización de la zona entéricas, por lo cual es de suma importancia la buena higiene y el cambio frecuente de pañales a fin de evitar este tipo de infecciones.

Aún existe antimicrobianos con buena sensibilidad para combatir las ITU, siempre y cuando se llegue a un correcto diagnóstico, entre estos antimicrobianos esta la nitrofurantoina con un $100 \%$ de sensibilidad, también se tiene buena efectividad frente a las cefalosporinas de tercera generación aunque existen algunas cepas productoras de BLEE.

Sería importante continuar con la línea de investigación, con un número más alto de pacientes con vejiga neurogénica, para poder evaluar las opciones de antimicrobianos que pueden ser utilizados en forma empírica y de esta manera poder iniciar un tratamiento en forma precoz y eficaz.

Las limitaciones del estudio fueron la difícil toma de muestra y el escaso número de pacientes con vejiga neurogénica que acuden al servicio, a pesar de tratarse de una entidad del sector público con fines exclusivos para la atención a las personas con discapacidad. 


\section{DECLARACION DE CONFLICTO:}

Las autoras expresan no tener ningún tipo de conflicto de interés.

\section{FUENTE DE FINANCIACIÓN:}

Este trabajo fue autofinanciado.

\section{REFERENCIAS BIBLIOGRAFICAS}

1. Cavagnaro $F$, Infección urinaria en la infancia. Rev Chil Infect. 2005; 22 (2): 161-8.

2. Miranda $L$, Rodríguez $M$, Peña $M$ de los $A$, Garrote MI. Evolución de las infecciones urinarias en pacientes con lesión medular y vejiga neurogénica en el CIREN, año 2006. Medwave [Internet]. 1 de abril de 2008 [citado 12 de diciembre de 2018];8(03). Disponible en: /link.cgi/Medwave/Enfermeria/2006/abril2 $008 / 2723$

3. Whiting $P$, Westwood $M$, Bojke L, Palmer S, RichardsonG, Cooper J, et al. "Clinical effectiveness and cost-effectiveness of tests for the diagnosis and investigation of urinary tract infection in children: a systematic review and economic model". Health Technol Assess. 2006; 10: 1-154.

4. Sánchez $M$, Lovera $D$, Arbo $A$, Infección Urinaria en Niños y Niñas internados: Características Clínicas y Microbiológicas. Rev. Inst. Med. Trop. 2015; 10 (1) 4-11.

5. Ardilla M, Rojas M, Santisteban G, et al. Infección Urinaria en pediatría. Repert.med.cir. 2015; 24(2): 113-122.

6. López C, Reyes G, Gallegos B, Reyes D, Reyes K. Bacteriología urinaria en niños con discapacidad. Enf.Inf.Microbiol. 2014; 34 (1):26-30.

7. Mohammad JH, Saffar MJ, Nemate I, Saffar $\mathrm{H}$, Khalilian AR. "Increasing antibiotic resistence among uropatohegens isolated during years 2006-2009: Impact on the empirical management". Int Braz $\mathrm{J}$ Urol. 2012; 38:25-32.

8. Saieh C, Garín E. Infeccion Urinaria: Lo que el pediatra debería conocer. Rev.med.clin.Condes. 2011; 22(2): 19196.

9. López M, Yanez V, Ramírez I, Díaz J, Rivas K. Estudio Epidemiológico y demográfico de la consulta externa de Nefrología Pediátrica. Revista Cubana de Pediatría. 2018; 90(1): 47-58.

10. Romero G, Conejero J, Planells I, Giménez M. Características de las infecciones urinarias en pacientes con vejiga neurógena según el sistema de vaciado vesical utilizado en comparación con pacientes sin vejiga neurógena. Actas urol esp. 2010; 34(3): 251-57.

11. Troche A, Araya S. Infección urinaria en pacientes con mielomeningocele. Rev.Inst. Med. Trop 2016; 11(1) 45-49. Doi: 10.18004/imt/2016011145-49.
12. Florentin $L$, Lascurain A, Báez D, Martínez $M$, Troche A. Consenso de Infección urinaria. Pautas de diagnóstico y tratamiento. Scielo.iics.una.py. Pediatr. 2011; 38(1).

13. Hill TC, Baverstock R, Carlson KV, Estey EP, Gray GJ, Hill DC, et al. Best practices for the treatment and prevention of urinary tract infection in the spinal cord injured population. Canadian Urological Association Journal. 16 de abril de 2013;7(3-4):122.

14. Garcia $L$, Esclarin $R$, Managemnet of urinary Tract infection in Patients with spinal Cord Injuries, Clinical Microbiology an Infection. 2003; 9:780-785.

15. Montero A y col. Pautas de actuación y seguimiento. Vejiga neurogénica en pacientes con lesión médular. Coloplast. Madrid 2015. 55p.

16. Troche $A$, Araya S. Infección urinaria en pacientes con mielomeningocele. Rev.Inst. Med. Trop 2016; 11(1) 45-49.Doi: 10.18004/imt/2016011145-49.

17. Pascuali P, Sevesi M, Costa C. Diagnóstico de infección urinaria en pacientes con vejiga neurogénica que practican cateterismo intermitente limpio. Rev Hosp Niños BAires Septiembre 2012; vol 54, número 246: 122-9.

18. Hernández $E$, Zamora $F$, Martínez $M$, Valdez M, Alberti E. Características epidemiológicas, clínicas y microbiológicas de las infecciones nosocomiales urinarias en las lesiones medulares espinales. Actas Urol Esp. 2007; 31(7):764-70.

19. Gonzalo-de-Liria C, Méndez M, Azuara M. Infección Urinaria. En: Junta Directiva de la Sociedad Española de Infectología Pediátrica (SEIP). Protocolos Diagnóstico y Terapéuticos en Pediatría: Infectología. Madrid: A.E.P; 2008. p.117-125

20. Martirén S, Sarkis C, Rosanova M. Infección urinaria en el paciente con mielomeningocele y vejiga neurogénica. Medicina Infantil. 2014; 21(4). http://www.medicinainfantil.org.arg.

21. Nakamura $T$, Komatsu M, Yamasaki $K$, Saori F. Miyamoto Y, Higuchi T, et al. Epidemiology of Escherichia coli, Klebsiella Species, and Proteus mirabilis strains producing extended-spectrum $\beta$ lactamases from clinical samples in the Kinki region of Japan". 2012; 137: 620-26.

22. Clinical and Laboratory Standards Institute (CLSI) 2017. Performance Standards for Antimicrobial Susceptibilyty Testing; $27^{\text {th }}$ 
Edition. Informational Supplement. M100 S26, 2017; 37 (1) 32-41.

23. Morales A, Arévalo $M$, Pérez F. Mecanismos implicados en la nefrotoxicidad producida por aminoglucócidos. Nefrología. 2000; 20:408-14.

24. Cullen IM, Manecksha RP, McCullagh E, Ahmad S, O'Kelly F, Flynn RJ, et al. The changing pattern of antimicrobial resistance within 42,033 Escherichia coli isolates from nosocomial, community and urology patient-specific urinary tract infections, Dublin, 1999-2009. BJU Int. abril de $2012 ; 109(8): 1198-206$. 